\title{
Control Strategies for Energy Efficiency at PNU's Metro System
}

\author{
Wafaa Saleh ${ }^{1,2, *,+}$, Shekaina Justin ${ }^{1}$, Ghada Alsawah ${ }^{1,3}$, Tasneem Al Ghamdi ${ }^{1}$ and Maha M. A. Lashin ${ }^{1,4}$ \\ 1 College of Engineering, Princess Nourah Bint Abdulrahman University, Riyadh 84428, Saudi Arabia; \\ SJThambi@pnu.edu.sa (S.J.); gaalsawah@pnu.edu.sa (G.A.); TSAlghamdi@pnu.edu.sa (T.A.G.); \\ mmlashin@pnu.edu.sa (M.M.A.L.) \\ 2 Transport Engineering School of Engineering and The Built Environment, Edinburgh Napier University, \\ Edinburgh EH10 5D, UK \\ 3 Mechanical Engineering Department, Higher Technological Institute, 10th of Ramadan 44629, Egypt \\ 4 Mechanical Department, Faculty of Engineering-Shoubra, Banha University, Banha 13518, Egypt \\ * Correspondence: wsshoukry@pnu.edu.sa \\ + Visiting Professor.
}

Citation: Saleh, W.; Justin, S.; Alsawah, G.; Al Ghamdi, T.; Lashin, M.M.A. Control Strategies for Energy Efficiency at PNU's Metro System. Energies 2021, 14, 6660. https:// doi.org/10.3390/en14206660

Academic Editor: Federica Raganati

Received: 2 September 2021

Accepted: 9 October 2021

Published: 14 October 2021

Publisher's Note: MDPI stays neutral with regard to jurisdictional claims in published maps and institutional affiliations.

Copyright: (c) 2021 by the authors. Licensee MDPI, Basel, Switzerland. This article is an open access article distributed under the terms and conditions of the Creative Commons Attribution (CC BY) license (https:// creativecommons.org/licenses/by/ $4.0 /)$.

\begin{abstract}
It is broadly acknowledged that there is an urgent need to reduce carbon-based mobility systems and increase renewable energy alternatives. The automotive industry is one of the greatest consumers of energy in the world. It is fronted with many challenges that aim at reducing carbon emissions. Renewable energy costs are getting cheaper and more cost effective. However, well devised design and control strategies are also needed in order to optimize any systems that are adopted in this field. Previous research shows that the energy consumption for non-traction purposes may be of the same scale as the energy used to move rolling stock, and in some cases even larger. The Kingdom of Saudi Arabia is very interested in the implementation of policies that aim at reducing energy consumption and encouraging renewable energy programs. Under its Vision 2030 development program, the Kingdom of Saudi Arabia is looking to produce 30\% of its energy from renewables and other sources, with solar energy playing an important role. The work presented in this paper is aimed at an investigation of design and control strategies to reduce energy consumption and to propose a cleaner source of energy to power Princess Nourah Bint Abdulrahman University's Automated People Mover (PNU-APM). Two areas of applications have been investigated for adopting these types of technology. Firstly, a p-v solar energy option that could be adopted for implementation in potential applications since the metro system is already in full operation using electricity. Secondly, design and control strategies including exploiting solar energy for a metro operation are discussed and investigated. A number of strategies to reduce heating, ventilation, and air conditioning (HVAC) load, which happens to be the biggest energy consumer, have been discussed. Results show great potential in energy savings with adopting $\mathrm{p}$-v solar sources as well as implementation of few suggested control strategies. Some deliberations of some of the drawbacks of solar energy are also offered.
\end{abstract}

Keywords: energy efficiency; metro system; transportation systems at educational institutions; control strategies; p-v solar systems

\section{Introduction}

Railway systems have a long history of being the backbone of any society as well as contributing significantly to their fuel consumption and environmental emissions. However, the railway services are operated by alternating current $(\mathrm{AC})$ electricity and therefore do not contribute to a large percentage of emissions at the end use at the global level. Therefore, it is often claimed to represent one of the utmost sustainable transport available options [1-3]. However, the electricity is not all clean; it comes from the grid. Thus, while it is clean at the end use, it is not at the origin, and it does have a negative impact on the environment. Most of the world's electricity is generated from carbon-based sources. Therefore, the railway industry will face the same prospect of needing to consider other sources of energy than electricity. Such implementation requires digital connectivity to 
be implemented. Although there have been concentrated research efforts in the area of renewable energy and mobility, their applications in railway transportation are still under consideration [1].

The vast design and development of the metro transit system have been devoted lately to optimizing energy consumption of that vital sector. Most countries around the world are seeming to increase the share of renewable energy systems within the total energy generation and use in order to reduce fuel consumption and greenhouse gas emissions [1,2]. The technological advances and information technologies have also played a major role in such development, for example, the automatic train operation (ATO) technology, realtime traffic information, as well as advancement in conventional technology [2-5]. The prices of many energy systems' components such as trackers, inverters, structural, and electrical components have seen sharp reductions in the range of 5-7\% [6-10]. Other possible applications of $\mathrm{p}-\mathrm{v}$ solar technologies could include utilizing $\mathrm{p}-\mathrm{v}$ solar to provide secondary energy for any means of transportation including vehicles and buses. Bus's sunroofs could include a p-v solar panel that can power trickle-charging batteries. Similarly, a lightweight PV layer can be utilized to the shape of airplane body parts such as wings to help provide energy to high-altitude aircrafts. Bartłomiejczyk [11] proposed p-v solar electrified urban transportation systems as a potential application of solar energy systems.

Whether such solutions could ever be used in larger systems such as whole metro systems or any other similar transportation system, where traffic is much higher and energy consumption is of a different order of magnitude, is still to be concluded. This depends on the costs and further development of the technology of the p-v solar panels as well as other contributing factors.

Solar radiation is a continual source of free energy that could be used by any sector [11-17]. Extensive research and developments in this area are being undertaken. The photovoltaic effect which implies the process of creation of voltage or electric current in a medium upon exposure to light has been achieved by exploiting the existing semiconductor technology. Solar energy is one of the most appealing sources of energy since it can be directly converted to electricity by photovoltaic converters (PVCs). There is more than one possible option of PV installations. Renewable energy sources including solar PV deployments have spread vastly recently, and the prices of solar systems have fallen considerably. For example, the average commercial price of PV elements has fallen down significantly over the past decade or so. A good number of publications have reported reduction in prices of solar PV systems [1-3]. Other energy components' prices have also dropped structural and electrical elements [7-9].

Another area of energy application is the energy consumed by heating, ventilation, and air conditioning (HVAC). HVAC systems generate a significant amount of energy consumption [10]. Hence, it is very important from an economic and environmental point of view to implement policies to reduce HVAC energy consumption. Control strategies can be very effective and low-cost policies for reducing energy consumptions [18-23]. The work presented in this paper is aimed at an investigation of design and control strategies to reduce energy consumption and to propose a cleaner source of energy to power Princess Nourah Bint Abdulrahman University in Riyadh, Kingdom of Saudi Arabia Automated People Mover (PNU-APM).

In a country such as Saudi Arabia, where the sun is available all year round, solar energy seems to be the obvious option for a renewable energy source. In addition, solar energy systems are easy to manage and economic to maintain. Several options are available to generate energy using solar $\mathrm{p}-\mathrm{v}$ generation. It should be mentioned, however, that some of the options discussed in this section seem to be for illustrative purposes only since trains are already in operation using electricity from the grid and since changing them to a $p-v$ system would not be cost effective. However, Saudi Arabia is a country in a development stage, and many new scenarios could well develop. Therefore, it seems worthwhile to calculate energy consumption and energy generation using the different options for raising awareness and for future references. 
All that said, it should be recognized nevertheless, that there are a number of downsides for any $\mathrm{p}-\mathrm{v}$ system. These include the comparatively high primary cost that would be involved in setting up a solar system. In addition, maintenance cost, depreciation, weather, the sun rays, and so on. There should be a comprehensive analysis of costs and benefits of any energy system to be built before decisions on the type and technology used.

\section{Methodology}

At the PNU campus, an $11.5 \mathrm{~km}$ automated guideway metro system has been created. As such, a light metro system of four lines, 22 two-carriages trains, and 14 stations started operation in 2012. Figure 1 below shows few images of the PNU metro. Each train operates at a maximum speed of $60 \mathrm{~km} / \mathrm{h}$ and has a capacity of 110 passengers. The technology used in the Riyadh metro is similar to the Copenhagen metro system. Currently, the metro is totally powered by the national grid. It is obvious that the amount of power needed to power the metro is huge and could be considered for changing the source of power to achieve sustainability benefits.

$$
\text { نظام النقل الآلي }
$$
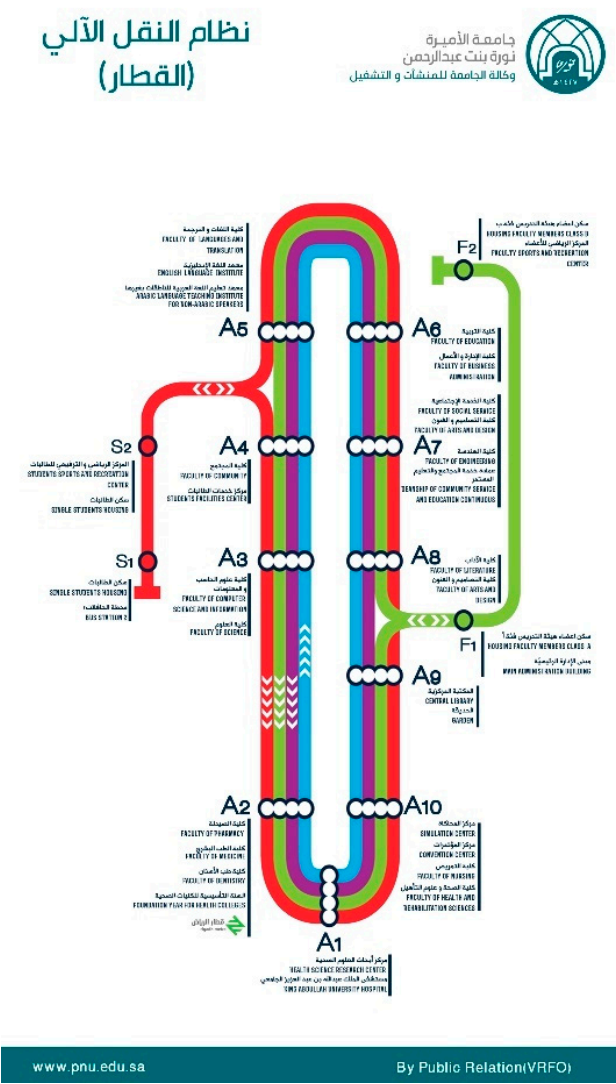

(a)

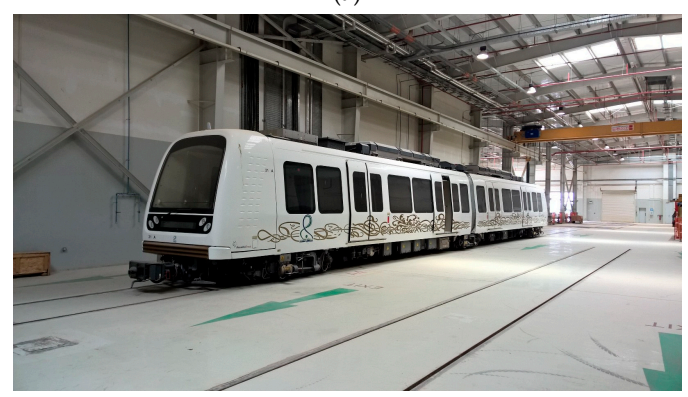

(b)

Figure 1. Cont. 


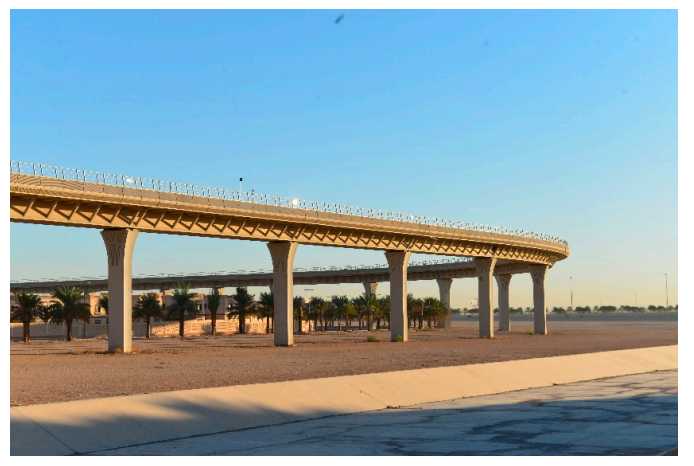

(c)

Figure 1. Images show PNU metro system. (a) Metro map. (b) Metro vehicle. (c) Metro railway.

To assess the amount of energy that is suitability needed to power the PNU trains, information regarding the operation and the amount of energy used per metro per vehicle and per day including weekend and seasonal data that have been provided by the PNU metro system is used. The amount of energy used per metro per vehicle is calculated based on a duration of $24 \mathrm{~h}$ /day. During the day, trains are in mainline from 07:30 to 17:30. They will be then parked in the depot for the rest of the day. This is excluding the weekend, where trains are mainly kept in depots (except a few trains that are used for periodical testing, checking, and getting prepared for following days operation). The information regarding energy consumption has been obtained from the operation department at PNU and is presented below. The daily energy consumption is $192 \mathrm{kWh}$ while the train is in the operational mode in the main line. The average daily distance covered is $84 \mathrm{~km}$ with no traction, of which ancillaries consume $23.45 \mathrm{kWh}$. During "out of service" or saving mode, ancillaries consume $4.5 \mathrm{kWh}$. This includes emergency lighting and train control systems (except the passenger information system PID).

Currently, the metro is totally powered from the national grid. It is obvious that the amount of energy needed to power the metro is huge. The topic of decarbonization is relevant in the current era. However, any case for replacing an already electrified system would be somewhat frail because of the costs and benefits in the appraisal. It is still interesting to view and assess the case of changing the energy mix of the country electric metro system that is in operation for comparative analysis. It is also useful for the purpose of demonstration for future sustainability considerations.

In order to be able to demonstrate the relevance of setting policies and programs for transforming the metro energy consumption to sustainable and renewable sources, it is very critical to assess the type and amount of energy required to operate this system. In the sections below, the methodology is centered around four main divisions as follows:

1. Evaluating the power requirement for the PNU metro system;

2. Assessing the possible energy generation using PV solar energy;

3. Evaluating control strategies for reducing traction energy;

4. Investigating design strategies for reducing HVAC load and generating electrical energy.

These four parts are discussed below.

\subsection{Power Requirement for the PNU Metro System}

Figure 2 and Table 1 show energy consumption by the PNU metro that was obtained from the University Metro operation unit. Figure 2 shows the average monthly energy consumption by the PNU metro system from the period of January 2019 to the period of March 2020. It should be noted that this energy consumption is for the case prior to COVID-19. 
Average monthly energy consumption by the PNU metro system

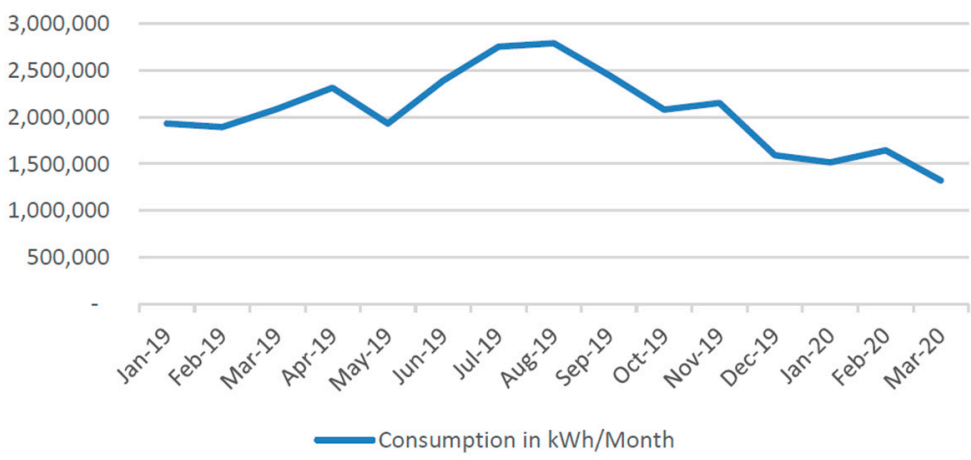

Figure 2. Average monthly energy consumption by the PNU metro system from the period of January 2019 to March 2020.

Table 1. Energy consumption by PNU metro during 2019 (kWh).

\begin{tabular}{cccc}
\hline $\begin{array}{c}\text { Energy } \\
\text { Consumption by } \\
\text { Metro kWh }\end{array}$ & $\begin{array}{c}\text { Energy } \\
\text { Consumption over } \\
\text { Summer kWh (2019) }\end{array}$ & $\begin{array}{c}\text { Energy } \\
\text { Consumption over } \\
\text { Winter kWh (2019) }\end{array}$ & $\begin{array}{c}\text { Annual Energy } \\
\text { Consumption kWh } \\
\text { (2019) }\end{array}$ \\
\hline Monthly Total & $20,960,292$ & $5,419,205$ & $26,379,496$ \\
\hline Monthly Average & $2,328,921$ & $1,806,402$ & 879,317 \\
\hline Daily Total & 698,676 & 180,640 & 73,276 \\
\hline Daily Average & $77,630.71$ & $60,213.39$ & \\
\hline
\end{tabular}

Table 1 shows energy consumption by PNU metro (kWh). From the table and gigure, it appears that from a daily perspective, the lowest average energy consumption for winter days is $53,126 \mathrm{kWh} /$ day, whereas the highest average energy consumption for summer days is $93,046 \mathrm{kWh} /$ day which is about $44 \%$ higher than it is in winter. From the results, the seasonal energy consumption for the metro system varies significantly. Most of the energy is consumed over the summer months. This reflects not only that the summer months extend from March-November of every year, but also mirrors the much higher temperature in summer compared to winter in the Kingdom of Saudi Arabia.

The table shows that about $80 \%$ of energy consumption by metro occurred during summer months $(20,960,292 \mathrm{kWh}$, which is about nine months per year) while only $20 \%$ of energy is consumed during winter months $(5,419,205 \mathrm{kWh}$, about three months per year). The total annual energy consumption is $26,379,496 \mathrm{kWh}$. On average, the monthly energy consumption in summer is about $2,328,921 \mathrm{kWh}$, while the average during winter months is $1,806,402 \mathrm{kWh}$. For example, the average energy consumption varies between 2,791,371 kWh per month during the month of August 2019 and 1,593,794 kWh per month during the month of December 2019. This is an over $29 \%$ increase during summer months compared to winter months. This is possibly due to the energy consumed in vast air-cooling systems that are used in the metro. It is very common to observe such seasonal variations in many sectors. California's energy demand reports that a peak of electricity consumption in the summer that is caused by the extensive use of electrically operated air conditioners and central air conditioning systems [14]. This problem can be mitigated by the use of demand response (DR) measures, including pricing measures and HVAC control programs and mechanisms [14].

\subsection{Energy Generation Using PV Solar Energy}

One possible option of energy generation using solar is to cover the surface of the train with $\mathrm{p}-\mathrm{v}$ film. This option might not be the most cost effective one given that the 
metro system is already up and running as discussed earlier. In any case, replacing an already electrified system would be somewhat frail because of the costs and benefits in the appraisal. The analysis is useful, however, for any possible future extensions of the metro or for newly introduced similar systems. It might also be interesting to view and assess the case of changing the energy mix of the country electric metro system that is in operation for comparative analysis. It is also useful for the purpose of demonstration for other applications and future sustainability considerations.

In this case, when the electrical energy generated is more than the energy consumed by the train, it can be supplied from the train to the station and other utilities, by using the existing infrastructure via the third rail. No additional inverters need to be installed. This option takes away no additional space and is aesthetically great. In addition to being a generator, it would considerably reduce the HVAC load, which is the biggest energy consumer. As the network's location is elevated above the ground level the deposit of debris during storms will be less. As the trains are moving most of the time, the temperature of the $\mathrm{p}-\mathrm{v}$ generator is minimized as the heat generated will be transmitted to the atmosphere effectively. This in turn will help to keep the efficiency of $p-v$ higher. However, the currently commercially available $\mathrm{p}-\mathrm{v}$ films are not quite efficient as the panels. Highly efficient perovskite films are expected to be available only from early 2022. As the manufacturing costs are bound to be low, this option with high efficiency is quite desirable in the medium-long term. This first option seems to be the most efficient option for our case.

In this case, the rooftop and side panels would be covered with perovskite solar films excluding the transparent glass windows. The mean energy generated from the rooftop per day $E_{r}$ is calculated using Equation (1) as follows:

$$
E_{r}=A \times I \times C \times e
$$

where:

$$
\begin{aligned}
& \text { A }=\text { Net rooftop area }=(29 \times 2.65)-4 \mathrm{~m}^{2} \\
& \mathrm{I}=\text { Daily solar incidence }=2350 / 365 \mathrm{kWh} \\
& C=\text { Conversion efficiency }=27 \% \\
& \mathrm{e}=\text { Exposure coefficient }=90 \% \\
& \mathrm{E}_{\mathrm{r}}=114 \mathrm{kWh}
\end{aligned}
$$

The mean energy generated from the side panels of a train is calculated as follows:

$$
E_{S}=[(63.3 \times 2.5)-12] \times 2350 / 365 \times 0.27 \times 0.37
$$

$\mathrm{E}_{\mathrm{s}}=94 \mathrm{kWh}$ lated as:

Total energy generated per day from each train from Equations (1) and (2) is calcu-

$$
E_{p}=E_{r}+E_{s}=208 \mathrm{kWh}
$$

Therefore, using $\mathrm{p}-\mathrm{v}$ film to cover the surface of the train could provide energy of up to about $30 \%$ of the total daily energy required (which is $698,676 \mathrm{kWh}$, Table 1 ) to operate the metro. It should be noted here that the magnitude of the energy produced by the solar panels does not affect the acceleration of the train. The energy generation from the solar panels at any instant is proportional to the solar incidence. In our system as the power lines of all the trains are looped to the third rail, when the total energy generated by the solar panels from all the trains is greater than the net consumption of all the trains, the surplus flows through the third rail to the utilities of the station. During instances when the energy generated by all the solar panels put together is less than the net energy requirement of the trains, the shortfall is withdrawn from the grid (as in the current scenario).

The other possible option involves setting up a detached $p-v$ solar generation facility with the aim of generating energy that would feed to the metro powering system. The choice of panels available in the market is high and the efficiency can be high particularly if tracking equipment are included. The downside of this is that it can require a lot of space, 
which might not be an issue for the university currently. However, it is an opportunity cost and should be considered. Further analysis for this option is vitally recommended for future research.

Another possible option is to set up a p-v solar generator on the roof of the metro- rail station. This option will save space and reduce the transmission lines. However, as most of the station roofs has a curved surface, installing and maintenance would be a problem. This option also will not be aesthetically appealing, as the station buildings are beautifully designed. From this section it seems that the first option is the most promising option for possible implementation. Further detailed studies and investigations of these options are also needed. Further analysis of this scenario is recommended for future research.

While the above discussions provided the advantages of constructing and utilizing $\mathrm{p}-\mathrm{v}$ solar facilitates, there are a number of drawbacks for any $\mathrm{p}-\mathrm{v}$ system that should also be discussed for completeness. These include, for example, the relatively high initial cost that would be needed to construct the system. Although the cost of installing solar systems have dropped significantly over the past few decades as a result of huge development of technology, the cost of solar installation is currently more expensive than electricity. This is particularly the case in a country such as Saudi Arabia where petrol prices are very low. The high cost of the p-v system is highly associated with the high cost of the PV solar panels and the cost of pure silicon that is the main component of the p-v solar system. Other contributing elements of cost include installation expenses, marketing, taxes, maintenance, and sales.

Furthermore, the efficiency of $p-v$ solar system depends greatly on the geographical location, weather, and the intensity of the sun rays. The other relevant factor is the electricity and other sources of power available and their rates and prices. Recycling and waste production of solar systems are also factors to be considered. Therefore, while there are potential benefits to installing $\mathrm{p}-\mathrm{v}$ solar panels, there are some cost and drawbacks associated with such systems that have to be taken into account.

\subsection{Evaluation of Control Strategies for Reducing Traction Energy}

As well as assessing the possible energy generation using PV solar energy, it is very important to evaluate control strategies for reducing traction energy. The main PNU metro line has a total length of $11.50 \mathrm{kms}$ and ten stations (A1, A2, . , A10), in addition to four service stations. The distance between stations in the main line equals to $600 \mathrm{~m}$ (A1 to A2, ..., A10 to A1) with the total main line distance equal to $6 \mathrm{~km}$; i.e., a round trip in the main line excluding F1, F2, S1, and S2 is $6 \mathrm{~km}$. Each train makes 14 round trips daily, which multiplied by 6 is $84 \mathrm{~km}$. The maximum speed of the two-car train is $60 \mathrm{~km} / \mathrm{h}$, the mean speed is $45 \mathrm{~km} / \mathrm{h}$, and the commercial speed is around $25 \mathrm{~km} / \mathrm{h}$. The maximum rate of acceleration is $1.0 \mathrm{~ms}^{-1}$ and the maximum rate of deceleration before is $0.9 \mathrm{~ms}^{-1}$.

From the information obtained from the metro operation department at PNU, it has been detected that during trips when the passengers using the metro rail are very limited, there are instances where there are very few passengers and instances where there are no passengers boarding or arriving at certain stations. Hence, two operational strategies are investigated that are based on these inferences:

\section{a. A dynamic scheduling strategy; \\ b. An advance departure strategy.}

For the dynamic scheduling strategy and for illustration purposes we consider one specific scenario. In this scenario, we assume the case of three stations (A6, A7, and A8). The distance between A6 and A7 is $1150 \mathrm{~m}$ and between A7 and A8 is $1150 \mathrm{~m}$. Figure 3 below shows a schematic diagram that represents the train movement from A6 to A8 (distance (a) and time (b)). 


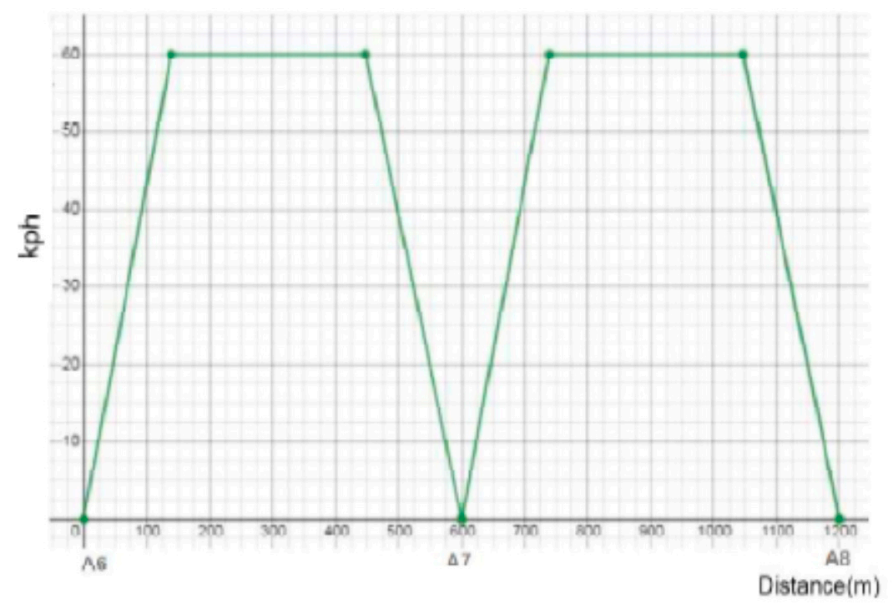

(a)

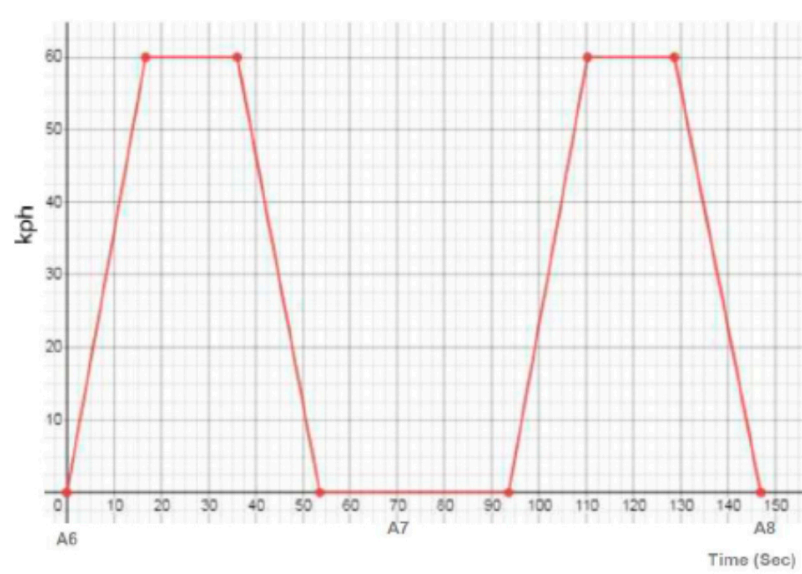

(b)

Figure 3. A schematic diagram represents the train movement from A6 to A8. (a) Distance. (b) Time.

In this scenario, the train starts traveling from station 6 to station 7 from zero speed with a rate of acceleration is $1.0 \mathrm{~ms}^{-1}$ until it reaches a maximum speed of $60 \mathrm{~km} / \mathrm{h}$. After cruising with this maximum speed for a distance until the point it starts to decelerate, the train then starts to decelerate at a rate of $0.9 \mathrm{~ms}^{-1}$ until it reaches zero speed (stationary).

The traction energy $\mathrm{E}_{6-7}$ that is required to move the train from $\mathrm{A} 6$ to $\mathrm{A} 7$ is calculated using Equation (2) as follows:

$$
\mathrm{E}_{6-7}=\mathrm{A}_{60}+\mathrm{C}_{60}+\mathrm{D}_{60}
$$

where:

$\mathrm{A}_{60}$ : Energy required to accelerate the train from 0 to $60 \mathrm{kph}$

$\mathrm{C}_{60}$ : Energy required to operate the train with a constant speed $60 \mathrm{kph}$ until the point it starts to decelerate.

$\mathrm{D}_{60}$ : Energy recovered during deceleration before stopping at $\mathrm{A7}$

$\mathrm{A}_{60}=\frac{1}{2} \mathrm{mv}^{2} \times \frac{1}{\eta}$

$\mathrm{m}($ Mass in $\mathrm{kg})=20,000 \mathrm{~kg}$

$\mathrm{V}($ Speed $)=60 \mathrm{kph}=16.67 \mathrm{~ms}^{2}=85 \%=\frac{1}{2} \times 20,000 \times(16.67) \times \frac{1}{0.85}=0.908 \mathrm{kWh}$

$\mathrm{C}_{60}=\left(\mathrm{C}_{\mathrm{r}} \mathrm{mg}+\mathrm{C}_{\mathrm{d}} \rho \mathrm{v}^{2} \mathrm{~A}\right) \mathrm{v} \times \frac{1}{\eta m} \times \frac{d}{D}$ where:

$\mathrm{C}_{\mathrm{r}} \& \mathrm{C}_{\mathrm{d}}$ (Coefficients of rolling resistance and coefficient of aerodynamic drag) $=$ $0.0005 \& 0.45$

$g=9.81 \mathrm{~ms}^{-1}$

$\rho=1.2 \mathrm{kgm}^{-3}$

A $($ Surface area $)=9 \mathrm{~m}^{2}$

$\eta \mathrm{m}=85 \%$

$\mathrm{d}$ (Distance traveled by the train at a constant speed of $60 \mathrm{kph})=308 \mathrm{~m}$

$\mathrm{D}$ (Distance traveled in $1 \mathrm{~h}$ ) $=60,000 \mathrm{~m}$

$\mathrm{C}_{60}=\left[0.0005 \times 20,000 \times 9.87+0.45 \times 1.2 \times(16.67)^{2}\right] \times 16.67 \times \frac{1}{0.85} \times \frac{308}{60,000} \mathrm{Wh}=$ $(98.1+1350.5) \times 16.67 \times \frac{1}{0.85} \times \frac{308}{60,000} \mathrm{Wh}=0.145 \mathrm{kWh}$

$\mathrm{D}_{60}=\frac{1}{2} \mathrm{mv}^{2} \times \eta_{g} \mathrm{~J}=\frac{1}{2} \times 20,000 \times(16.67)^{2} \times 0.05=0.656 \mathrm{kWh}$.

$\mathrm{E}_{60}=0.908+0.45-0.656=0.397 \mathrm{kWh}$

On a typical working day, the train does 14 trips covering 140 stations over a distance of $84 \mathrm{~km}$. The energy required for traction for 14 round trips $\mathrm{E}_{\mathrm{t}}$ is:

$\mathrm{E}_{\mathrm{t}}=14 \times 10 \times 0.397 \mathrm{kWh}=55.58 \mathrm{kWh}$.

The energy required for the train from $A_{6}$ to $A_{8}$ is $E_{68}=$ twice the energy required for the train from A6 to A7 $=0.794 \mathrm{kWh}$. 
Now we consider a scenario where during off peak hours, there are zero passengers to board and alight in station A7, the train therefore can skip station A7 and save energy. In this case, the train would accelerate at the same pace as previously until it reached a speed of $31.5 \mathrm{kph}$, moving at a constant speed after that in order to maintain its original arrival schedule, until it started to decelerate before arrival at A8 as per the original schedule. In this case, the traction energy $\mathrm{E}_{31.5}$ that is required to move the train from $\mathrm{A} 6$ to $\mathrm{A} 8$ using the new time and distances is seen in see Equation (3) and Figure 4 below.

$$
\mathrm{E}_{31 \cdot 5}=\mathrm{A}_{31 \cdot 5}+\mathrm{C}_{31 \cdot 5}+\mathrm{D}_{31 \cdot 5}
$$

where:

$$
\begin{aligned}
& \mathrm{A}_{31 \cdot 5}=0.25 \\
& \mathrm{C}_{31 \cdot 5}=0.172 \mathrm{kWh} \\
& \mathrm{D}_{31 \cdot 5}=0.18 \\
& \mathrm{E}_{31 \cdot 5}=0.242 \mathrm{kWh}
\end{aligned}
$$

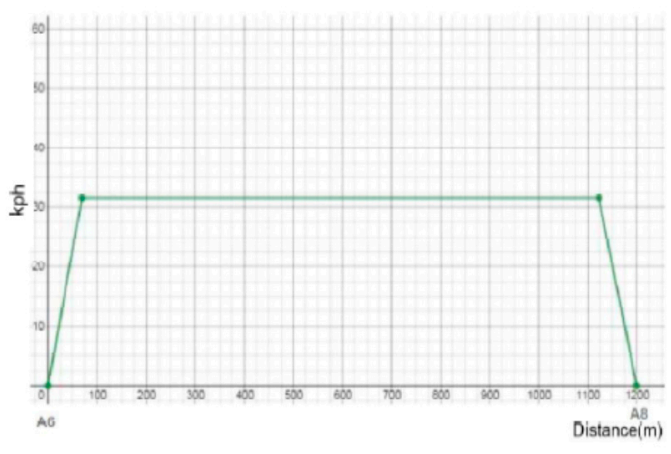

(a)

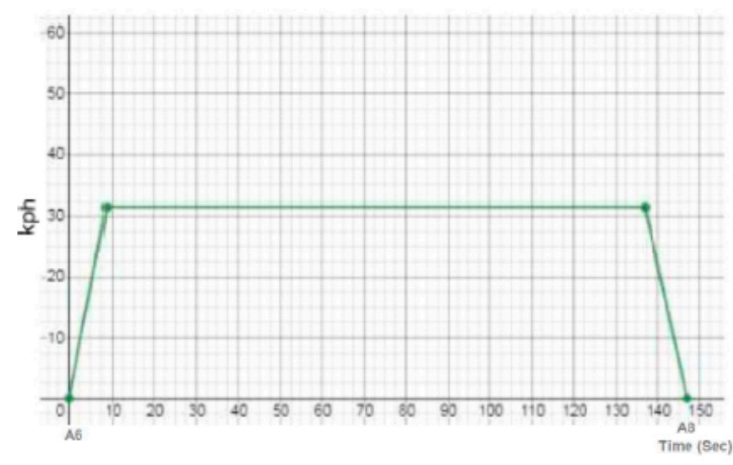

(b)

Figure 4. A schematic diagram represents the train movement (distance (a) and time (b)) from A6 to A8 directly without stopping at A7.

Therefore, implementing this dynamic scheduling strategy, and skipping A7, the net energy saved is $69.52 \%$ of the previous requirement to move from A6 to A8.

The second control strategy is the advance departure strategy. In this case, the aim is to advance the departure time when all the number of passengers who have registered using the input device completed entering the train. When the boarding is completed within less time than scheduled, then the train would be allowed to depart earlier rather than waiting when no passengers are aborting. For example, if the train is supposed to leave after $10 \mathrm{~s}$ from arrival, but all passengers aligned within eight seconds, then the train is possible to depart two minutes earlier. In this scenario, it is assumed that there is no published time schedule for the arrival and departure of trains as it is the case at PNU. Instead, the proposal is to use the registering device in order to optimize performance and reduce waiting time. In that case, the second subroutine takes over and commands the train in the speed so that the train arrives at the next station at the original scheduled time (Figure 5a,b illustrates the strategy). The savings in traction energy in this condition are calculated to be about $68 \%$. 


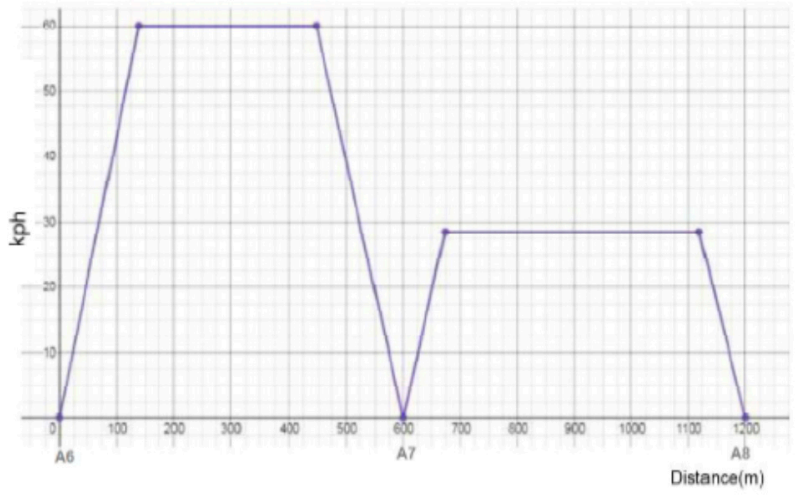

(a)

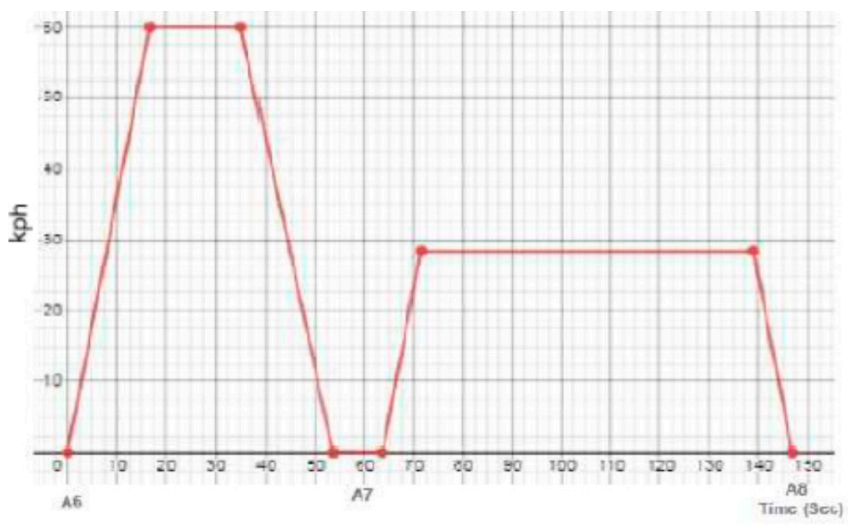

(b)

Figure 5. A schematic diagram represents the train movement from A6 to A8 directly with dynamic speed variability. (a) Distance. (b) Time.

\subsection{Design Strategies for Reducing HVAC Load and Generating Electrical Energy}

Another sector that needs energy is the energy consumed by heating, ventilation, and air conditioning (HVAC). HVAC systems generate a significant amount of energy consumption. For example, 33\% of the total building energy consumption is consumed in HVAC [10]. It is evident, therefore, that it is both economically and environmentally beneficial to implement policies to reduce HVAC energy consumption. Control strategies can be very effective and low cost polices for reducing energy consumptions [10-13]. To assess the amount of energy that is suitability needed to power the PNU trains, the following assumptions are made:

The inference from the readings on the reference day is that the energy consumed by the heating, ventilation, and air conditioning (HVAC) system in the train is about $132 \mathrm{kWh}$. This value is calculated as: $192.00-(55.58-4.54)$.

For the energy generation, as the roof area of the train is $76.85 \mathrm{~m}^{2}$ and plane surface area of the vertical sides is about $175 \mathrm{~m}^{2}$, the $\mathrm{p}-\mathrm{v}$ generation potential from the roof and the sides are about 125 and $83 \mathrm{kWh}$, respectively, when multiple-junction perovskite p-v thick film is wrapped on the roof and the sides, excluding the glass surfaces. This is a total of $208 \mathrm{kWh}$ of generation from the $\mathrm{p}-\mathrm{v}$ generator. An aerogel insulator sheet is sandwiched between the $\mathrm{p}-\mathrm{v}$ film and the metal body. As the time for which the train to be exposed to sunlight should be maximized for maximum generation, the effectiveness of the insulator material is very important. As the outside temperature and the direct solar incidence age make up for the main components of the HVAC load, whereas the air exchange and passenger loads are comparatively lower, the importance of insulation in controlling the heat transfer is apparent. The solar p-v film will contribute to the reduction of HVAC load significantly along with the insulation.

Furthermore, a 30\% reduction in HVAC load and a 35\% reduction in traction demand will bring down the energy consumption in this case to about 133 from $192 \mathrm{kWh}$. With $208 \mathrm{kWh}$ of generation from the p-v generator, this provides a surplus of about $75 \mathrm{kWh}$ from each train in operation. The trains which are not in operation when exposed to sunlight would generate about $208 \mathrm{kWh}$. When 20 trains are exposed to sunlight and 15 are in operation on an average any given day, a surplus of about $2165 \mathrm{kWh}$ generated flows through the third rail which can be used to partially power the stations. The conversion efficiency of single junction perovskite film is 23\%, perovskite/silicon tandem cell is $29.1 \%$, and perovskite multi-junction thick film is about 33\%. Considering an efficiency of $29 \%$, the average surplus electrical energy generated from the bus roof top and the side surface of the train is $2511 \mathrm{kWh}$.

The voltage regulator interfaced between the solar generators has its output terminal connected to the junction between the third rail contact terminal and the inverter input 
terminal maintains an output voltage incrementally greater than the voltage of the third rail $(750 \mathrm{~V})$. As all the trains are connected to a third rail via the contact blade, the trains that generate surplus will feed to the rail and the trains which require additional energy will withdraw from the rail. As inverters and rectifiers are already part of the existing system, the solar $\mathrm{p}-\mathrm{v}$ generators can be easily integrated with the system.

When the train is directly exposed to sunlight, the solar incidence on the roof is about $60 \mathrm{~kW}$ and an equivalent incidence reaches the sides of the train. As the body is fabricated using metal sheets, a large quantity of the incidence is absorbed, raising its temperature considerably. When the train is encapsulated with $\mathrm{p}-\mathrm{v}$ film and an aerogel sheet sandwiched between the metal sheet and the $\mathrm{p}-\mathrm{v}$ film, the heat transferred to the metal body is reduced significantly. The heat transferred is calculated using Equation (4) as follows:

$$
\mathrm{H}=\frac{\Delta \mathrm{T}}{\left(\frac{\mathrm{t}}{\mathrm{kA}}\right)}
$$

where:

$\Delta \mathrm{T}$ : Difference of temperature between the surfaces $\left(25^{\circ}\right)$

A: Area of the insulation

$\mathrm{t}$ : Thickness of insulator $(4 \mathrm{~mm})$

$\mathrm{k}$ : Coefficient of thermal conductivity of insulator $\left(0.014 \mathrm{~W} / \mathrm{m}^{2} \mathrm{k}\right)$

A: Surface Area

$\mathrm{H}=\frac{25}{4 \times 10^{3} /(0.014 \times 76.85)}=6721 \mathrm{~W}=6.72 \mathrm{~kW}$

Therefore, this is an illustration that while the trains are moving most of the time, the temperature of the $\mathrm{p}-\mathrm{v}$ generator will be minimized as the heat generated will be transmitted to the atmosphere effectively. This in turn will help to optimize the efficiency of $\mathrm{p}-\mathrm{v}$.

\section{Conclusions}

While PV solar panels have many disadvantages such as high costs and huge waste production, there are lots of potential benefits. For the Kingdom of Saudi Arabia and its Vision 2030, investigations of benefits and potential of solar energy are of relevance. In this paper, the readings of the present consumption of energy needed for operating metro system at Princess Nourah Bint Abdelrahman University in Riyadh in Saudi Arabia were obtained and segmented to identify the daily and seasonal patterns of energy consumption. The theoretical values of the main energy components were calculated. The gaps between them were analyzed and suitable control strategies and design strategies were formulated. The various options available for improving renewable energy were discussed and assessed.

The possible options that are considered include setting up a detached $\mathrm{p}-\mathrm{v}$ solar generation facility with the aim of generating energy that would feed to the metro powering system. The results suggest that using $\mathrm{p}-\mathrm{v}$ film to cover the surface of the train could provide energy of up to about $30 \%$ of the total required daily energy to operate the metro. Other possible options have also been briefly discussed including setting up a p-v solar generator on the roof of the metro rail station and covering the surface of the train with $\mathrm{p}-\mathrm{v}$ film to allow unused energy generated to be reused in other parts of the building or even to be fed into the grid. In this case, when the electrical energy generated exceeds the energy consumed by the train, the excess can be delivered to the station and other utilities via existing infrastructure of the building. The possible drawbacks of $\mathrm{p}-\mathrm{v}$ solar energy systems have also been deliberated. These include high initial and operational cost, weather and sun dependency, and high waste production.

The HVAC load, which happens to be the biggest energy consumer, was discussed and a few options were suggested to reduce the load. As the trains are moving most of the time, the temperature of the $\mathrm{p}-\mathrm{v}$ generator will be minimized as the heat generated will be transmitted to the atmosphere effectively. This in turn will help to optimize the efficiency of p-v. The analysis suggests that a 30\% reduction in HVAC load and a 35\% reduction in traction demand will bring down the energy consumption, in this case, to about 133 
from $192 \mathrm{kWh}$. With $208 \mathrm{kWh}$ of generation from the $\mathrm{p}-\mathrm{v}$ generator, this provides a surplus of about $75 \mathrm{kWh}$ from each train in operation. While the trains are not in operation but exposed to sunlight, it would be possible to generate about $208 \mathrm{kWh}$. When 20 trains are exposed to sunlight and 15 are in operation, on average at any given day, a surplus of about $2165 \mathrm{kWh}$ generated flows through the third rail which can be used to partially power the stations. The conversion efficiency of single junction perovskite film is $23 \%$, perovskite/silicon tandem cell is $29.1 \%$, and perovskite multi-junction thick film is about $33 \%$. Considering an efficiency of $29 \%$, the average surplus electrical energy generated from the bus roof top and the side surface of the train is $2511 \mathrm{kWh}$. Further research in this area is strongly recommended.

It should be mentioned that while some of the options discussed in this paper could be seen as a bit impractical since that the metro system is already up and running, the provided analysis is beneficial in a way that it could provide useful information for any future similar or an extension of the existing system. Presenting the benefits and shortcomings of installing $\mathrm{p}-\mathrm{v}$ systems would prove a valuable tool for decision makers and operators who are involved in setting up new energy systems. However, any case for replacing an already electrified system would be somewhat weak because of the costs involved. The presented analysis is only useful for the purpose of demonstration for future sustainability considerations, depending on the policy objectives of the country, resources available and geographical information, when the best energy system can then be recognized.

Some further possible applications of the proposed $\mathrm{p}-\mathrm{v}$ solar technologies could include a local transportation shuttle system that would be used to complement the Riyadh metro system. Once Riyadh metro system is opened, there will be a need for shuttle transport to take passengers to and from the metro to their houses. These shuttle services could well be designed to be powered by $\mathrm{p}-\mathrm{v}$ solar means.

Other areas of applications in transportations include utilizing $\mathrm{p}-\mathrm{v}$ solar to provide secondary energy for automated vehicles including buses, cars, boats, and airplanes. Such systems can include a p-v solar thin panels to provide power to batteries. Lightweight $\mathrm{PV}$ can also conform to the shape of airplane wings to help power high-altitude aircraft. Whether such solutions could ever be used in larger systems such as whole metro systems or any other similar transportation system, where traffic is much higher and energy consumption is of a different order of magnitude is still to be concluded. This will depend on the costs and further development of the technology of the $\mathrm{p}-\mathrm{v}$ solar panels as well as other contributing factors.

Author Contributions: Data curation, W.S. and G.A.; Formal analysis, S.J., T.A.G. and M.M.A.L.; Investigation, W.S. and S.J.; Methodology, W.S. and G.A.; Project administration, W.S.; Writingoriginal draft, W.S.; Writing-review \& editing, S.J., G.A., T.A.G. and M.M.A.L. All authors have read and agreed to the published version of the manuscript.

Funding: This research project was funded by the Deanship of Scientific Research, Princess Nourah Bint Abdulrahman University, through the Program of Research Project Funding after Publication, grant No 41- PRFA-P-39.

Institutional Review Board Statement: Not applicable.

Informed Consent Statement: Not applicable.

Data Availability Statement: Not applicable.

Conflicts of Interest: The authors declare no conflict of interest.

\section{References}

1. International Energy Agency (IEA). Energy and Climate Change, World Energy Outlook Special Report; OECD/IEA: Paris, France, 2015; p. 109.

2. Candelise, C.M.; Winskel, R.J. Gross the dynamics of solar PV costs and prices as a challenge for technology forecasting. Renew. Sustain. Energy Rev. 2013, 26, 96-107. [CrossRef]

3. Obeidat, F. A comprehensive review of future photovoltaic systems. Sol. Energy 2018, 163, 545-551. [CrossRef] 
4. Sivaram, V.; Kann, S. Solar power needs a more ambitious cost target. Nat. Energy 2016, 1, 1-3. [CrossRef]

5. Rajendran, L.; Thirugnana, S. Urban Metro Elevated Station to Generate Solar Power. Int. J. Integr. Eng. 2018, 10, 156-166. [CrossRef]

6. AlKuhaimi, A.A.; AlMogait, E.S. Bridging E-Gaps at PNU by using Alternative Energy. Procedia-Soc. Behav. Sci. 2012, 64, 297-305. [CrossRef]

7. Feng, J.; Li, X.; Liu, H.; Gao, X.; Mao, B. Optimizing the Energy-Efficient Metro Train Timetable and Control Strategy in Off-Peak Hours with Uncertain Passenger Demands. Energies 2017, 10, 436. [CrossRef]

8. Miyatake, M.; Ko, H. Optimization of Train Speed Profile for Minimum Energy Consumption. IEEJ Trans. Electr. Electron. Eng. 2010, 5, 263-269. [CrossRef]

9. Ondraczek, J.; Komendantova, N.; Patt, A. WACC the dog: The effect of financing costs on the levelized cost of solar PV power. Renew. Energy 2014, 75, 888-898. [CrossRef]

10. Strantzali, E.; Aravossis, K. Decision making in renewable energy investments: A review. Renew. Sustain. Energy Rev. 2016, 55, 885-898. [CrossRef]

11. Bartłomiejczyk, M. Potential Application of Solar Energy Systems for Electrified Urban Transportation Systems. Energies 2018, 11, 954. [CrossRef]

12. Saleh, W.; Justin, S.; Alsawah, G.; Malibari, A. Lashin MMA An Investigation into Conversion of a Fleet of Plug-in-Electric Golf Carts into Solar Powered Vehicles Using Fuzzy Logic Control. Energies 2021, 14, 5536. [CrossRef]

13. Manie, N.; Pattanaik, B. Zeta DC-DC converter based on MPPT technique for BLDC application. Int. J. MC Sq. Sci. Res. 2019, 11, 1-12.

14. Li, N.; Wei, P.; Yu, L.; Ji, J.; Zhao, J.; Gao, C.; Li, Y.; Yin, Y. Small Dynamically Switchable Multi Colour Electrochromic Films; Wiley Online Library: Hoboken, NJ, USA, 2019.

15. Hossain, M.I.; Qarony, W.; Sainan Ma Zeng, L.; Knipp, D. Perovskite/Silicon tandem solar cells: From detailed balance limit calculations to photon management. Nano Micro Lett. 2019, 11, 1-24. [CrossRef] [PubMed]

16. Nageib, A.; Elzafarany, A.M.; Elhefnawy, M.H. Using Smart Glazing for Reducing Energy Consumption on Existing Office Building in Hot Dry Climate; Taylor \& Francis: Abingdon, UK, 2020.

17. Yao, Q.; Xue, Q.; Li, Z.; Zhang, K.; Zhang, T.; Li, N.; Cao, Y. Graded 2D/3D Perovskite Heterostructure for Efficient and Operationally Stable MA-Free Perovskite Solar Cells. Adv. Mater. 2020, 32, 2000571. [CrossRef] [PubMed]

18. Avgerinou, M.; Bertoldi, P.; Castellazzi, L. Trends in Data Centre Energy Consumption under the European Code of Conduct for Data Centre Energy Efficiency. Energies 2017, 10, 1470. [CrossRef]

19. Avci, M.; Erkoc, M.; Rahmani, A.; Asfour, S. Model predictive HVAC load control in buildings using real-time electricity pricing. Energy Build. 2013, 60, 199-209. [CrossRef]

20. U.S. DOE. Buildings Energy Data Book. 2009. Available online: http://buildingsdatabook.eren.doe.gov (accessed on 20 August 2021).

21. Aswani, A.; Master, N.; Taneja, J.; Culler, D.; Tomlin, C. Reducing transient and steady state electricity consumption in HVAC using learning-based model-predictive control. Proc. IEEE 2012, 100, 240-253. [CrossRef]

22. Burke, W.; Auslander, D. Low-Frequency Pulse Width Modulation Design for HVAC Compressors; The ASME: San Diego, CA, USA, 2009

23. California Energy Commission. California Energy Demand: 2000-2010; California Energy Commission: Sacramento, CA, USA, 2000. 